\title{
Laudatio for Professor Dr. Dr. h.c. Syed M. Qaim
}

\author{
A. Chatt
}

Received: 3 March 2010/Published online: 30 March 2010

(C) Akadémiai Kiadó, Budapest, Hungary 2010

Professor Dr. Dr. h.c. mult. Syed Muhammad Qaim was brought up in Pakistan. He obtained both his B.Sc. (1958) and M.Sc. (1961) from the Government College and Punjab University in Lahore, Pakistan. He received his Ph.D. in Nuclear Chemistry in 1964 from Liverpool University and D.Sc. in Applied Nuclear Science in 1977 from Birmingham University in England. He then received his Habilitation in Nuclear Chemistry in 1993 from Universität zu Köln, Germany.

Upon graduation with Ph.D., Dr. Qaim joined Birmingham University as a Research Associate (1964-66). He then served as a Senior Scientific Officer, Atomic Energy Centre in Lahore, Pakistan during 1966-68. He was an Alexander von Humboldt Fellow at Johannes Gutenberg-Universität Mainz, Germany (1968-70). Dr. Qaim then joined the Nuclear Research Centre, Jülich, Germany in 1970. He spent the next 36 years at the Centre in various capacities such as a Scientist (1970-75), a Group Leader (1975-85), and a Division Leader (1985-2006) in the Institute of Nuclear Chemistry. He also served as an Acting Director (1995-96), and as the Vice-Director (1996-2006)

Prepared by Professor Dr. A. Chatt (Halifax, Canada), Chairman of the Hevesy Medal Award Selection Panel 2008, President of the International Committee on Activation Analysis (ICAA). Narrated by Professor Dr. L. Wojnarovits (Budapest, Hungary), Co-Chairman of the 7th International Conference on Nuclear and Radiochemistry (NRC-7), Budapest, 2008.

Hevesy Medal and Scroll presented by Professor Dr. Dr. h.c. Tibor Braun (Budapest, Hungary), Editor-in-Chief, Journal of Radioanalytical and Nuclear Chemistry.

A. Chatt $(\bowtie)$

SLOWPOKE-2 Facility, Trace Analysis Research Centre, Department of Chemistry, Dalhousie University, Halifax, NS B3H 4J3, Canada

e-mail: A.Chatt@Dal.Ca of the Institute of Nuclear Chemistry. Additionally, since 1997 he has been a Professor of Nuclear Chemistry at Universität zu Köln and is still teaching there. Since 2006, after his retirement, he is a Guest/Advisor at his old Institute of Nuclear Chemistry, Research Centre Jülich. Furthermore, he holds a UNESCO-funded Research Professorship at the Third World Academy of Sciences (TWAS) in Trieste, Italy.

Professor Qaim has very broad research interests in fundamental as well as applied aspects of nuclear chemistry, from Mössbauer spectroscopy, nuclear spectroscopy, nuclear reactions, and nuclear data to cyclotron-produced radionuclides. His fundamental work in Mössbauer spectroscopy dealt with ${ }^{57} \mathrm{Co}$ incorporated in 32 different metal lattices via electrolytic deposition and high temperature diffusion. He was the first one to show that the linebroadening of the source in certain metals is caused by quadrupole splitting. The four pioneering papers published on this topic in the late sixties have become classic.

His fundamental work in nuclear spectroscopy and nuclear reactions dealt with decay properties of nuclei. In the sixties Prof. Qaim discovered five new radionuclides, namely ${ }^{88} \mathrm{Nb},{ }^{88} \mathrm{Mo},{ }^{89} \mathrm{Mo},{ }^{120} \mathrm{Xe}$ and ${ }^{213} \mathrm{~Pb}$, and characterized several others such as ${ }^{120} \mathrm{I},{ }^{130} \mathrm{I},{ }^{132} \mathrm{Cs},{ }^{240} \mathrm{~Np}$. In the seventies he concentrated on low-yield complex particle emission reactions, e.g. $(\mathrm{n}, \mathrm{t}),\left(\mathrm{n},{ }^{3} \mathrm{He}\right),\left(\mathrm{n},{ }^{7} \mathrm{Be}\right)$ and $\left(\mathrm{p},{ }^{7} \mathrm{Be}\right)$, which could only be studied via a combination of activation techniques with very precise radiochemical separations and low-level counting techniques as well as statistical model calculations based on the Hauser-Feshbach formalism. Prof. Qaim was awarded the Eötvös Lorand Medal of the Hungarian Physical Society in 1988 for his pioneering work in this field.

In recent years, Prof. Qaim has become more interested in the fundamental aspects of the formation of isomeric 
states in nuclear reactions. Through extensive experimental and theoretical investigations involving neutrons and charged particles Prof. Qaim is the first scientist to show that the isomeric cross section ratio is primarily governed by the spins of the two states concerned and not by their separation energies. The spin distribution of the level density was shown to be mass dependent, also for the first time.

Prof. Qaim has also made significant contributions to the applied aspects of nuclear research through his work on nuclear data and cyclotron-produced radionuclides. He studied nuclear data related to fusion reactor technology (FRT) and medicine. In the case of FRT, he placed emphasis on neutron-induced reactions on first wall structural materials, first using a $14 \mathrm{MeV}$ neutron generator and later a quasi-monoenergetic neutron source constructed at the compact cyclotron CV 28. Again, he made extensive use of radiochemical methods and several of the hydrogen and helium producing reactions, such as (n,np), (n,n $\alpha)$, etc. were observed for the first time. Furthermore, he characterized several long-lived soft radiation-emitting activation products such as ${ }^{45} \mathrm{Ca},{ }^{55} \mathrm{Fe}$, and ${ }^{63} \mathrm{Ni}$.

Regarding nuclear data for medical applications, Prof. Qaim devoted his efforts to the measurement and evaluation of excitation functions of nuclear reactions relevant to the optimization of known and potentially useful production routes of almost all major medically interesting radionuclides, starting with ${ }^{11} \mathrm{C},{ }^{18} \mathrm{~F}$, etc. and ending with ${ }^{195 \mathrm{~m}} \mathrm{Pt},{ }^{201} \mathrm{Tl}$, etc. He developed novel methods of sample preparation using highly enriched materials, elegant radiochemical separations and sophisticated methods of radioactivity measurement.

As far as cyclotron-produced radionuclides are concerned, Prof. Qaim placed emphasis on the development of novel production routes, high-current solid, liquid and gaseous targets, efficient methods of separation, quality control of the desired product, and recovery of the enriched target material for reuse. In recognition of his outstanding contributions to this field, Prof. Qaim received the prestigious JARI Medal Award and Pergamon Press Prize in 1990. In recent years, he developed several new radionuclides for medical applications. Some of these radionuclides, such as ${ }^{64} \mathrm{Cu},{ }^{73} \mathrm{Se},{ }^{86} \mathrm{Y},{ }^{94 \mathrm{~m}} \mathrm{Tc},{ }^{120} \mathrm{I}$, and ${ }^{124} \mathrm{I}$ are presently attracting worldwide attention.

In addition to his original research contributions and publications of more than 340 papers and 4 books, Prof.
Qaim has invested time with great enthusiasm for the dissemination of knowledge in nuclear and radiochemistry. During his last 37 years at Jülich, he provided research guidance to about 60 guest scientists and 25 Ph.D. students. He gives special lectures at several universities and summer schools, for example at the ICTP Trieste. He carries many international professional responsibilities. $\mathrm{He}$ is presently the Chairman of the International Nuclear Data Committee (INDC) of the IAEA and the Coordinating Editor of Radiochimica Acta.

Prof. Qaim has been honoured in several countries through Fellowships and awards. He is a Fellow of the Royal Society of Chemistry, London (1974), a Fellow of the Institute of Physics, London (1974), an Honorary Fellow of the Hungarian Physical Society (1988), a Foreign Fellow of the Pakistan Academy of Sciences (1990), a Foreign Fellow of the Pakistan Nuclear Society (1997), a Foreign Fellow of the Pakistan Institute of Chemists (1998), a Fellow of the Islamic World Academy of Sciences (1994), and an Associate Fellow of the Third World Academy of Sciences (2001) for services to the cause of science in the Third World countries. He is an Honorary Professor, Govt. College University, Lahore, Pakistan (2003). He received a Medal of Honour of the Egyptian Atomic Energy Authority (EAEA) for long-standing cooperation in the development of science at the EAEA (2005). Prof. Qaim received a Medal and Certificate of Merit of the Egyptian Association of Nuclear Physicists (EANP) for services to the cause of science in Egyptian universities (2005). Prof. Qaim was awarded the Title "Civis Universitatis honoris causa" (translated as Honorary Citizen) by the Kossuth University, Debrecen, Hungary (1995) and he is the First recipient of this title. Later he was awarded the Title "Doctor honoris causa" (translated as Honorary Doctorate) by the same University (1999). Recently he has been awarded an Honorary Doctorate by the Yorker International University, New York/Milan/ Florence (2007). Prof. Qaim received the Civil Award "Sitara-i-Imtiaz" from the President of Pakistan (1999) for services to the cause of science in Pakistan. For his outstanding contributions to radiochemistry, Prof. Qaim has been selected for the Becquerel Medal Award (2008) of the Radiochemistry Group of the Royal Society of Chemistry, London, which he will get in November this year.

It is indeed a pleasure to honour Professor Dr. Dr. h.c. mult. Syed M. Qaim with the Hevesy Medal Award 2008. 